Von der gefundenen Menge des Stickstoffs ist rund $0,10 \mathrm{ccm}$, von der des Sauerstoffs $0,05 \mathrm{ccm}$ in Abzug zu bringen; diese Menge an Luftgasen war nämlich in den verwendeten $10 \mathrm{ccm}$ Salzsäure gelöst.

Es soll nun das Ergebnis einiger Versuche mitgeteilt werden. Destilliertes Was s or von $15-20^{\circ}$ wurde bei annähernd $760 \mathrm{~mm}$ Luftdruck mit Luft gesättigt, ciann die Bestimmung mit $255 \mathrm{ccm}$ Wasser in beschriebencr Weise vorgenommen. An gelösten Luftgasen, bezogen auf $0^{\circ}$ und $760 \mathrm{~mm}$ Druck, wurcie gefunden:

\begin{tabular}{|c|c|c|c|}
\hline$t$ & $\mathrm{O}_{2}$ & $N_{2}$ & zusammen \\
\hline $15^{\circ}$ & $1,83 \mathrm{ccm}$ & $3,48 \mathrm{ccm}$ & $5,31 \mathrm{ccm}$ \\
\hline $16^{\circ}$ & 1,77 & 3,41, & 5,18 \\
\hline $17^{\circ}$ & 1,71 & $3,35 \quad$, & 5,06 \\
\hline $18^{\circ}$ & 1,71 & 3,28 & 4,99 \\
\hline $19^{\circ}$ & 1,65, & 3,21, & 4,86 \\
\hline $20^{\circ}$ & 1,66 & 3,17, & 4,83 \\
\hline
\end{tabular}

Es sollen nun die jetzt gefundenen Werte mit den früher gefundenen genauen Werten ${ }^{5}$ ) verglichen werden. In $1000 \mathrm{cem}$ destilliertem Wasser sinci bei $760 \mathrm{~mm}$ Luftdruck die folgenden Raummengen an Gasen, berogen auf $0^{\circ}$ und $760 \mathrm{~mm}$ Druck, gelöst:

Nach vorliegenden Versuchen.

\begin{tabular}{|c|c|c|c|}
\hline $\mathrm{t}$ & $O_{2}$ & $\mathrm{~N}_{2}$ & zusammer \\
\hline $15^{\circ}$ & $7,2 \mathrm{ccm}$ & $13,7 \mathrm{~cm}$ & 20,9 \\
\hline $16^{\circ}$ & 6,9, & 13,4 & 20,3 \\
\hline $17^{\circ}$ & 6,7 & 13,1 & 19,8 \\
\hline $18^{\circ}$ & 6,7, & 12,9 & 19,6 \\
\hline $19^{\circ}$ & 6,5 & 12,6 & 19.1 \\
\hline $20^{\circ}$ & 6,5 & 12,4 & 18,9 \\
\hline
\end{tabular}

Nach den früheren Versuchen.

$13,51 \mathrm{com} 20,55 \mathrm{com}$

$16^{\circ}$

$7,04 \mathrm{ccm} \quad 13,51 \mathrm{ccm}$

$20,55 \mathrm{ccm}$

13,25

20,14,

$6,75 " 13,00 \%, \quad 19,75$,

$18^{\circ}$

$6,6, " 13,00 \quad$,

19,38

19,02,

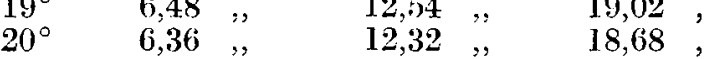

Fin Vergleich der Zahlen zeigt, daß mit dem beschriebenen Verfahren die im Wasser gelösten Luftgase mit genügender Genauigkeit bestimmt werden können. Ist größere Genauigkeit erwünscht, so bestimmnt man nur die Gesamtmenge der gelösten Gase, den Sauerstoff dagegen jodiometrisch.

Mit dem beschriebenen Verfahren wurde der Gehalt an Luftgasen in ciner $\mathrm{Me}$ e rwasserprobe (spez. Gewicht: 1,025 ) bestimmt, dic bei $20^{\circ}$ mit Luft gesättigt war. In $1000 \mathrm{ccm}$ wurden $10,3 \mathrm{ccm} \mathrm{N}_{2}$ und $5,4 \mathrm{ccm} \mathrm{O}_{2}$ gefunden; der auf jodometrischem Wege gefundene Sauerstoffgehalt betrug $5,30 \mathrm{ccm}$.

Es mögen schließlich noch die Ergebnisse einiger Versuche hier angeführt werden, die Herr $\mathrm{Z}$ ol t á $n \mathrm{~T}$ ót $\mathrm{h}$ bei der Untersuchung des Budapester Leitung $\mathrm{s}$ w a s sers (vom 3./5. 1915) auf dessen Gehalt an Luftgasen erhielt.

In $1000 \mathrm{ccm}$ Leitungswasser wurde gefunden:

$\begin{array}{ccc}\mathrm{O}_{2} & \mathrm{~N}_{2} & \text { zusammen } \\ 4,1 \mathrm{ccm} & 17,9 \mathrm{ccm} & 22,0 \mathrm{ccm} \\ 4,2, & 17,6, & 21,8 ", \\ 4,2, & 17,6 ", & 21,8,\end{array}$

Die Utbereinstimmung der Zahlen untereinander zeigt wieder, daß das beschriebene Verfahren zur Bestimmung der in natürlichen Wässern enthaltenen Iuftgase sich zur Anwendung empfiehlt.

[A. 61.]

5) L a n d o It - B örnstein - R oth, Physikalisch-Chemisehe Tabellen, IV. Aufl., S. 60 ?

\section{Neues Reagensglasgestell}

zum Gebrauch fïr Vorlesungen und bei technisch-colorimetrischen Arbejten.

\section{Vou Dr. K. Hormann.}

Wer selbst Fxperimentalvorträge in Chemie zu halten, ocier wer auch nur solchen Vorlesungen beigewohnt hat, kennt jene Verlegenheit des Vortragenden, die Reagensgläser mit den ausgeführten Versuchen auf dem Fxperimentiertisch so unterzubringen, daß sie von den Zuhörern cieutlich gesehen und noch laingere Zeit betrachtet wercien kömmen, ohne andererseits bei neuen Versuchen in Wege zu sein und ciurch Cimfallen und Zerbrechen Schadien anzurichten. Vielfach werden Bechergläser, Kelchgläser und ähnliches zum Weglegen der Röhren benutzt, doch wird dadurch in allen äiesen Fällen zum nindesten die Sichtbarkeit gestört.

Das neue Reagensglasgestell will versuchen, dem tibelstande abzuhelfen, indem es gestattet, die Reagensgläser durch einfaches Anlehnen an die Püickwand bis zu den lileinsten Flüssigkeitsmengen, bis zum Boden hin sichtbar aufzustellen.

Die nach vorn erhöht stehende Bodenplatte trägt dic gegen die Senkrechte etwas gencigte Rückwandplatte, welche zur Aufnahme der Reagierzylinder mit sechs halbrunden Rinnen versehen ist, die ihrerseits in sechs napfartige Vertiefungen der Bodenplatte münden. Die durch

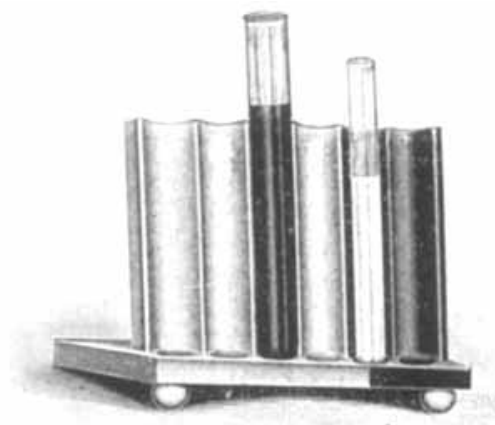

Versuche ermittelte Neigung der beiden Platten macht ein Umfallen oder Ausgleiten der Reagensgläser nach vorn unmöglich und gestattet trotzdem den Zuhörern, selbst die kleinste Niederschlagsmenge auf dem Boden der Zylinder aus der Ferne zu erkennen. Sie erlaubt aber auch, Reagensg]äser jeder beliebigen Größe, von den kleinsten gebräuchlichen bis zu Massen von $200 \times 30 \mathrm{~mm}$ in dieser Weise aufzustellen.

Je nach der Natur des Niederschlags oder der Farbtönung der Reaktionen wird man ein Gestell aus weißen oder schwarzem Porzellan vorziehen.

Nicht nur bei Vorlesungen, sondern auch in der Praxis der Fabriken wird das neue Reagensglasgestell als $\mathrm{Be}$ quemlichkeit empfunden werden, $z$. B. überall da, wo man, wie im Brauerei- oder Färbereilaboratorium, mit technischcolorimetrischen Arbeiten zu tun hat.

Wie schon erwähnt, wird das Gestell in der Regel aus Porzellan gefertigt, auf besonderen Wunsch aber auch aus Holz geliefert. Porzellan besitzt neben größter Stabilität und größter Widerstandsfähigkeit gegen chemische Einflüsse den besonderen Vorzug unbedingter Sauberkeit.

Das neue Gestell steht unter D. R. G. M.-Schutz und wird in drei Ausführungen: ganz weiß, ganz schwarz, mit vior weißen und zwoi schwarzen Feldern zum Einheitsstïckpreis von $5,75 \mathrm{M}$ von der Firma Iudwig Hormuth, Inhaber $W$. Vetter, Heidelberg, in den Handel gebracht.

[A. 86.] 